\title{
DISCUSSION ON “MINIMUM VERTICAL REINFORCEMENT IN RC WALLS: THEORETICAL REQUIREMENTS FOR LOW AND HIGH DUCTILITY DEMANDS"
}

\section{LETTER TO THE EDITOR}

Dear Sir,

Re: "Minimum vertical reinforcement in $\mathrm{RC}$ walls: Theoretical requirements for low and high ductility demands", by Yiqiu Lu and Richard S. Henry, Vol. 50, No. 4, December 2017.

I enjoyed reading this article in the Bulletin, along with earlier publications by the authors on the same research topic.

Referring the article (titled above), and specifically to the discussion of Equation 12 on Page 476, the likely material strengths in walls is stated as considering the following factor:

\section{"1.2 multiplier on $f^{\prime}{ }_{c}$ to represent the average target compressive strength given in NZS 3104:2003 relative to the specified strength ( $5^{\text {th }}$ percentile)"}

In NZ construction practise the 1.2 multiplier is often not always appropriate, as eluded to below:

1. The 1.2 multiplier relates to the target compressive strength which concrete producers are required to achieve as a minimum above that which is specified by engineers. In reality, most plant engineers will target a strength greater than 1.2 times the specified strength (to avoid penalties). The probable value for this multiplier is more likely on the order of 1.35-1.40. A statistical survey of plant records around NZ could be carried out to more accurately quantify this ratio for standard concretes. In the context of this article, this difference could increase the minimum reinforcing steel by $5-10$ percent.

2. In comparison to normal concrete, self-compacting concrete (SCC) mixes have a much wider statistical distribution with respect to compressive strength. It is inferred that this also results in a high distribution in concrete tensile strength. The article does not refer to SCC, which is being used more popular in NZ construction.

Both points 1 and 2 above are important, however the main purpose of this letter is to provide further discussion on point 2 .

\section{Self-Compacting Concrete (SCC) in NZ Construction}

SCC is commonly used for highly reinforced (congested) components. In context of the article, this scenario has no issues with the minimum longitudinal reinforcement required by concrete design codes. However, this is not the only scenario where SCC is being used in NZ construction. Other factors see SCC being used for lightly reinforced structural components, for example:

- In precast yards, for a combination of factors such as congested reinforcement, less labour for vibration and early lifting as, by default, SCC is a richer mix with a highearly age strength.

- In situ pours, as contractors may adopt SCC as an alternative to standard concrete to seek potential economic and/or programme advantages. Although SCC has a higher material cost (driven by cement content, fine aggregates and admixtures), there are practical advantages of reducing labour on site.

- On residential projects with high-specified architectural concrete finishes.

\section{Ratio of Supplied SCC Strength to Specified Strength}

For commonly specified concrete grades (30-40 MPa) using SCC mixes, average compression test results typically show 28 day strengths of $60-70 \mathrm{MPa}$ (or higher).

"Self-compacting concrete (SCC) has inherently high strength (typically >70MPa), which will require large reinforcing contents. Designers need to be aware of this, and may need to avoid use of SCC for this reason" [1]

The plant engineer's primary mix-design objective is to achieve good fresh properties, finding the balance point in workability (including pumping) and stability of the mix by keeping the aggregates in suspension. Strength is a secondary focus. Overall this results in SCC mixes having a much wider strength distribution in comparison to normal concrete mixes.

Anecdotally, two major NZ concrete producers have indicated that the ratio between the average target strength and the specified strength is on the order of 1.5-1.6. This stated value range is based on well-tested "stable" grade $30 \mathrm{MPa}$ and 40 MPa SCC mix designs. It is understood that this ratio is likely to higher for "newly developed" SCC mixes, as these have not been subjected to as many trials and tests at the plant.

The compressive strength of SCC far exceeds the specified strength upon which the structural engineer has based their design calculations on. Higher than expected concrete strengths is not a new issue to design engineers. SESOC [2] describes a RC panel which had a specified $f^{\prime}{ }_{c}$ of $40 \mathrm{MPa}$, yet a SCC mix was use which had a 7 days compression strength of $90 \mathrm{MPa}$.

\section{Empirical Relationship between Concrete Compressive and Tensile Strength}

As eluded to above, higher than expected strength values are primarily of concern due to effects on the flexural-tensile material responses of both the concrete and reinforcing steel. The article provides a good outline of the flexural theory for ductile RC walls. The minimum quantity of longitudinal reinforcement aims to ensure that the reinforcing tensile capacity exceeds that of the concrete. The same principle applies to the RC beams, slabs, and columns.

In code equations, the concrete tensile strength is commonly expressed empirically in terms of the specified concrete compressive strength, $f^{\prime}{ }_{c}$. As the article notes, Amendment 3 of NZS 3101:2006 [3] expresses the concrete tensile strength as:

$$
f_{c t}=0.52 \sqrt{f^{\prime}{ }_{c}}
$$


The article also refers to the Model Code 2010 [4] empirical relationship:

$$
f_{c t}=0.3\left(f^{\prime}{ }_{c}\right)^{2 / 3}
$$

The above empirical relationships are a helpful simplification for design equations. Both expressions are based on a large amount of historic test data for standard concrete, and therefore do not apply to SCC. There are inherent differences in the mix ingredients, for example SCC uses smaller $13 \mathrm{~mm}$ aggregates.

The question raised for concrete researchers - can a reliable empirical relationship be established for SCC mixes? This is a challenging task, especially due to the difficulty in obtaining reliable tensile strength values which typically exhibit a large degree of scattered due to:

- Variation between different concrete tensile strength test set-ups (indirect "Brazilian" test, direct uniaxial testing, and modulus of rupture testing).

- The extent of cement hydration; member geometry and differential shrinkage; the proportion, size and angularity of course aggregate; and segregation of constituent materials in casting [5].

A significantly large amount of tension and compression test samples are required to accurately quantify the tensile strength of SCC. A small number of tests will not reliably capture the sample-to-sample strength variability.

\section{SCC Specification and Quality Assurance}

SCC is considered "Special Concrete" under NZS 3104:2003. The implication for special concrete is that the design engineer has the responsibility (and control) to nominate performance requirements, and a means of complying.

Until such time that there is better information on SCC strength properties, structural engineers may choose to specify a maximum compressive strength and/or a maximum tensile strength. The tensile testing set-up generally requires more effort (as eluded to above) and a larger number of samples, which involves some additional cost.

\section{Effect of "High-strength" SCC on Minimum Reinforcement}

NZS 3101 [3] defines the minimum reinforcement as a function of $\sqrt{f^{\prime}}$. By simply assuming that the "minimum" 1.2 factor (for standard concrete) can be replaced with 1.6 for SCC (as discussed earlier), the minimum reinforcement is increased by a factor of:

$$
\sqrt{(1.6 / 1.2)}=1.16
$$

The article proposes Equations 11 for the minimum reinforcement in walls, which is a function of $\left(f^{\prime}{ }_{c}\right)^{2 / 3}$ based on [4]. Again, by simply replacing the 1.2 factor with a 1.6 factor, the minimum reinforcement is increased by a factor of:

$$
(1.6 / 1.2)^{2 / 3}=1.21
$$

The increases shown above are non-negligible, and should therefore be taken into consideration in the structural design.

Substituting the value of 1.6 in for 1.2 may too crude, however this was done for simplicity and is in the absence of better information for the tensile strength of SCC (as eluded to above). As noted earlier, less stable SCC mixes are likely to have a ratio which is greater than 1.6, thus further increasing the minimum reinforcement.

\section{Influence of Loading Rate for Varying Concrete Strength}

On Page 476 of the article, Equation 12 also includes:

\section{"1.2 multiplier on $f_{c t}$ for the increase in concrete tensile strength due to dynamic loading rates;"}

Lower grades of concrete exhibit a greater strength dynamic increased factor (DIF) in comparison to higher grades of concrete. In experimental tests on bond mechanics in RC [5], it was found that:

- For $f^{\prime}{ }_{c}=30 \mathrm{MPa}$, the bond strength DIF is around 1.30

- For $f^{\prime}{ }_{c}=60 \mathrm{MPa}$, the bond strength DIF is around 1.10

These bond strength test results are deemed to be relevant on the basis that bond strength is also a function of the concrete tensile strength. Similar conclusions were reached in the literature review presented in [6].

- For $f^{\prime}{ }_{c}=25 \mathrm{MPa}$, the stated tensile strength DIF is 1.42

- For $f^{\prime}{ }_{c}=60 \mathrm{MPa}$, the stated tensile strength DIF 1.09

Retaining a single DIF for the concrete tensile strength is preferred for simplicity. Based on the current literature, the proposed 1.2 loading-rate multiplier seems reasonable for SCC.

\section{Closing Remarks}

This letter does not dispute the article above, rather it has extended the discussion to be more specific to NZ concrete supply. Self-compacting concrete (SCC) batched in NZ plants exhibits a wide ranging distribution of strength. Structural design engineers should be aware of high strength SCC as this has consequences for lightly reinforced components. This letter has offered up topics where further research is beneficial.

Discussions with James Mackechnie (Concrete NZ) and Dene Cook (Firth Industries) provided the motivation for writing this letter. Alistair Russell (Holmes Consulting) is acknowledged for providing feedback on a draft of this letter.

\section{Gareth Morris (Member)}

Structural Engineer, Holmes Consulting, Christchurch

\section{REFERENCES}

1 SESOC (2011). "Practice Note - Design of Conventional Structural Systems Following Canterbury Earthquakes" Structural Engineering Society of New Zealand, December. http://canterbury.royalcommission.govt.nz/documents-by$\mathrm{key} / 20111221.1908$

2 SESOC (2011). "Preliminary Observations from Christchurch Earthquakes". Prepared for the Canterbury Earthquakes Royal Commission. http://canterbury.royalcommission.govt.nz/documents-bykey/20111205.1533

3 Standards New Zealand. (2006). "NZS3101: Parts 1 and 2 Concrete Structures Standard-New Zealand". Standards New Zealand, Wellington.

4 Fédération Internationale du Béton, fib (2012). "Model Code 2010 - Final Draft, Volume 2". FIB Bulletin No. 66, Lausanne, Switzerland.

5 Morris, G. J. (2015). "Experimental Evaluation of Local Bond Behaviour of Deformed Reinforcing Bars in Concrete Structures", Masters of Engineering Thesis, University of Canterbury.

6 Concrete NZ (2018) "Literature Review on Rate of Loading Effects on Reinforced Concrete" Report submitted to the Ministry of Business, Innovation \& Employment (MBIE), Wellington. 


\section{AUTHORS' RESPONSE}

The authors appreciate the comments from Gareth Morris and welcome additional discussion on this important topic. In the early part of his letter Mr. Morris questioned the appropriateness of the 1.2 factor that is intended to represent the target average compressive strength when compared to the specified (5th percentile) strength. It should be noted that the factors used in Eq. 12 were originally developed by the NZS 3101:2006 Amendment 3 committee where they were subject to robust examination and discussion. Committee members representing the ready-mix industry did examine the average measured strengths (compression and tension) from available $\mathrm{NZ}$ data and were satisfied that this factor was appropriate in addition to the expression for tensile strength.

The issue of SCC strengths is critical to minimum reinforcement and has been raised by SESOC following the Canterbury earthquakes (as cited in the letter). The commentary to the new minimum reinforcement provisions in NZS 3101:2006 Amendment 3 also highlight the issue:

C11.3.12.3 (par. 2): "It should be noted that $\mathrm{f}^{\prime} \mathrm{c}$ is the specified 28-day concrete strength, and that the actual concrete strength may be significantly higher. Particular attention should be given to situations where a higher than specified concrete strength may be used, such as in precast construction and when using selfcompacting concrete."

While the potential for significantly higher average strengths when using SCC (or other specialty mixes) is important to consider, it is difficult to capture this in a design standard requirement due to the wide range of possible scenarios. Structural engineers are encouraged to give attention to the specified concrete strengths used during design, which may need to be revisited after the construction methodology is decided. For example, specified concrete strengths of $f^{\prime} c=30$ MPa should not be used during design when it is known that the component will be precast or use a SCC mix. The idea of including an upper bound concrete strength in the specification has been mooted during discussions but may place unreasonable constraints on contractors and concrete suppliers. We would welcome further discussion on how this issue could be addressed by either design specifications or standards.

Regards,

Rick Henry and Yiqiu Lu

University of Auckland 